\title{
Effect of ageing on the availability of heavy metals in soils amended with compost and biochar: evaluation of changes in soil and amendment properties
}

\author{
A. Venegas, A. Rigol*, M. Vidal \\ Departament de Química Analítica. Universitat de Barcelona, Martí i Franquès 1-11, 08028- \\ Barcelona (Spain) \\ *Corresponding author: $\quad$ Telephone: (+34) 93403 9276; Fax: (+34) 934021233 \\ E-mail address: annarigol@ub.edu (A. Rigol)
}

\begin{abstract}
Remediation strategies using soil amendments should consider the time-dependence of metal availability to identify amendments that can sustainably reduce available pollutant concentrations over time. Drying-wetting cycles were applied on amendments, soils and soil+amendment mixtures, to mimic ageing at field level and investigate its effect on extractable $\mathrm{Cd}, \mathrm{Cu}, \mathrm{Ni}, \mathrm{Pb}$ and $\mathrm{Zn}$ concentrations from three contaminated soils. The amendments investigated were municipal waste organic compost and biochars. The amendments, soils and mixtures were characterised by their physicochemical properties at different ageing times. The amendments were also characterised in terms of sorption capacity for $\mathrm{Cd}$ and $\mathrm{Cu}$. The sorption capacity and the physicochemical properties of the amendments remained constant over the period examined. When mixed with the soils, amendments, especially the compost, immediately reduced the extractable metals in the soils with low $\mathrm{pH}$ and acid neutralisation capacity, due to the increase in $\mathrm{pH}$ and buffering capacity of the mixtures. The amendments had a relatively minor impact on the metal availability concentrations for the soil with substantially high acid neutralisation capacity. The most important changes in extractable metal concentrations were observed at the beginning of the experiments, ageing having a minor effect on metal concentrations when compared with the initial effect of amendments.
\end{abstract}

Keywords: metal availability, organic amendments, biochar, remediation, drying-wetting cycles. 


\section{Introduction}

The accumulation of heavy metals in soils is a worldwide problem because these pollutants can have a large impact on the environment and human health. Total metal concentration is a value often used to establish the degree of contamination of a soil. However, reliance solely on this term impedes the accurate assessment of risk, particularly if no further knowledge on the contaminant's availability exists (Adriano 2001).

Heavy metal availability depends on sorption reactions with mineral and organic soil phases, which are controlled by $\mathrm{pH}$, ionic strength, surface area and the concentration of complexing ligands, among other factors (Hooda 2010; Kabata-Pendias 2011). Understanding the key interaction mechanisms that govern metal mobility in soils has allowed researchers to focus on soil remediation approaches that reduce metal availability in soils (Khan et al. 2004). In situ chemical stabilisation through the addition of amendments has relatively low costs and facilitates the treatment of large polluted areas (Kumpiene et al. 2008). Organic wastes generated from biomass are promising candidate amendments for this remediation approach, as they can regulate soil $\mathrm{pH}$ and provide specific sorption sites for heavy metal binding (Lee et al., 2004). However, organic amendments may also remobilize metals if they have high dissolved organic matter contents able to form soluble complexes with metals in the soil solution (Khokhotva and Waara 2010). Furthermore, chemical processes such as oxidation, hydrolysis, depolymerisation and microbial degradation of the organic amendment may modify the availability of heavy metals (Martínez et al. 2003; Nwachukwu and Pulford 2008). Experiments investigating the effects of mineral additions and organic amendments on $\mathrm{Cd}, \mathrm{Zn}$ and $\mathrm{Pb}$ leaching in contaminated soils showed a decrease in $\mathrm{Cd}$ and $\mathrm{Zn}$ leaching when the $\mathrm{pH}$ of the applied mixtures increased, a result that remained over time (Houben et al. 2012). In contrast, those amendments with a high dissolved organic carbon (DOC) content provoked an increase in $\mathrm{Pb}$ leaching at the initial time; at later times, changes in $\mathrm{Pb}$ leaching corresponded with changes in the DOC content. Beesley et al. (2010) investigated the initial effects of 
biochar and greenwaste compost on the pore water concentrations of $\mathrm{Cd}, \mathrm{Zn}$ and $\mathrm{Cu}$ in a mildly acidic soil, as well as the impacts of ageing experiments over time. In that experiment, $\mathrm{Cu}$ concentrations in soil solution increased with the addition of amendments as a result of an increase in the DOC content, but the initial remobilisation had decreased by the end of the ageing period. On the other hand, an increase in the $\mathrm{pH}$ of the soil mixtures at the initial time resulted in a decrease in the leachable concentrations of $\mathrm{Cd}$ and $\mathrm{Zn}$, which remained until the end of the experiment.

The effects of ageing on organic amendments added to contaminated soils over time appear to be dependent on the amendment and metal considered. This work examines the stability over time of organic amendment-treated soils more deeply. Specifically, our study evaluated the effect of three organic wastes (a municipal compost and two biochar materials) on $\mathrm{Cd}, \mathrm{Cu}, \mathrm{Ni}$, $\mathrm{Pb}$ and $\mathrm{Zn}$ availability in three contaminated soils with contrasting characteristics. We also analysed the effects of ageing on metal leachability in soils, amendments and soil+amendment mixtures by applying drying-wetting cycles to simulate the field conditions. An evaluation of the changes in metal interaction in the target samples over time was carried out using sorption and leaching tests to elucidate whether the ageing process could significantly affect the efficiency of organic amendments in mediating metal availability over time.

\section{Materials and methods}

\subsection{Samples}

Three amendments and three contaminated soils were used in this study. The amendments were a biochar derived from tree barks $(\mathrm{BF})$ and a biochar derived from vine shoots (BS), both of which were produced by pyrolysis at $400^{\circ} \mathrm{C}$, as well as a compost derived from municipal organic waste (MOW2). 
Of the three soils, one was contaminated with pyritic sludge particles and acidic wastewater (RIB), and two were contaminated by continuous exposure to mining activities (S15 and ALJ). All soils originated from the Andalusia autonomous region in the southwest of Spain. All samples were dried, sieved trough a $2 \mathrm{~mm}$ mesh, homogenised and stored in bottles before analysis. The methods used for sample characterisation are described in the Supplementary Material.

\subsection{Preparation of soil+amendment mixtures: ageing experiment}

The soil+amendment mixtures were prepared with a $10 \%$ dose of the amendment. $40 \mathrm{~g}$ of amendment were homogeneously mixed with $360 \mathrm{~g}$ of soil. The mixtures were placed in plastic pots and subjected to a maximum of ten drying-wetting cycles (DW) to simulate a natural ageing process that might occur in the field. This was done to examine the effect of soil ageing on metal extractability. Samples of amendments and soils were also submitted to DW cycles to better understand the ageing process and its effect on metal extractability in the mixtures.

Every DW cycle consisted of wetting the sample to its respective field capacity (FC), maintaining the samples in closed vessels at room temperature for $72 \mathrm{~h}$ and later drying them at $40^{\circ} \mathrm{C}$ for $48 \mathrm{~h}$. In the case of the soil+amendment mixtures, the $\mathrm{FC}$ was estimated by averaging the FC of the soil and the amendment, taking into account the amendment dose. Samples were collected after 0,5 and 10 DW cycles (thus defining the T0, T1 and T2 samples, respectively). Two replicates were conducted for each experiment. Cation exchange capacity (CEC) was determined at $\mathrm{T} 0$ and $\mathrm{T} 2$ in the amendments, whereas $\mathrm{pH}$, acid neutralisation capacity (ANC) and DOC were determined in all samples at T0 and T2. The extractable metal contents were determined in soils, amendments and mixtures at T0, T1 and $\mathrm{T} 2$. 


\subsection{Sorption tests}

\subsubsection{Quantification of $K_{d}$}

Sorption experiments for $\mathrm{Cd}$ and $\mathrm{Cu}$, representatives of the examined heavy metals, were conducted on amendments at $\mathrm{T} 0, \mathrm{~T} 1$ and $\mathrm{T} 2$, according to recommended protocols (OECD 2000; Sastre et al. 2006). The amendment samples ( $2 \mathrm{~g})$ were pre-equilibrated with $50 \mathrm{~mL}$ of a $0.01 \mathrm{~mol} \mathrm{~L}^{-1} \mathrm{CaCl}_{2}$ solution for $16 \mathrm{~h}$ using an end-over-end shaker. After the preequilibration time, known volumes of the metal solution $(\mathrm{Cd}$ and $\mathrm{Cu})$ were added to create at least four different initial metal concentrations up to $0.8 \mathrm{meq} \mathrm{L}^{-1}$. These represented the concentrations observed in different environmental contamination episodes (Nwachukwu and Pulford 2008). The volume of the metal solutions added to the batches was kept below $1 \%$ of the total volume of the suspension to avoid significant changes in the solid-liquid ratio. The resulting suspensions were shaken end over end for $24 \mathrm{~h}$. Subsequently, suspensions were centrifuged, the supernatants were filtered through a $0.45-\mu \mathrm{m}$ filter and the metal concentrations were determined by inductively coupled plasma-optical emission spectrometry (ICP-OES) as described in the Supplementary Material. The sorbed metal concentrations were calculated by quantifying the metal concentration in the initial solution $\left(C_{i}\right)$ and in the equilibrium solution $\left(C_{e q}\right)$, as follows:

$$
C_{s o r b}=\frac{\left(C_{i^{-}} C_{e q}\right) V}{m}
$$

where $C_{\text {sorb }}$ is the sorbed concentration of metal (meq kg-1), $m$ is the mass of the amendment (kg) and $V$ is the volume of the contact solution (L). The solid-liquid distribution coefficient, $K_{d}\left(\mathrm{~L} \mathrm{~kg}^{-1}\right)$, was calculated for each initial concentration as the ratio between the amount of the target metal sorbed onto the amendment, $C_{\text {sorb }}\left(\mathrm{meq} \mathrm{kg}^{-1}\right)$, and the amount of metal at equilibrium in the final contact solution, $C_{e q}\left(\operatorname{meq~} \mathrm{L}^{-1}\right)$, using the following equation:

$$
K_{d}=\frac{C_{s o r b}}{C_{e q}}
$$




\subsubsection{Fitting of sorption isotherms}

The experimental sorption isotherms were fitted to Freundlich and linear models. The Freundlich model is represented by the following equation:

$$
C_{s o r b}=K_{f} C_{e q}^{N}
$$

where the $K_{f}$ and $N$ parameters were obtained by fitting $C_{s o r b} v s$. $C_{e q}$. The $K_{f}$ parameter describes the partitioning of the metal between the solid phase and the liquid phase; and $N$ relates to the heterogeneity of the sorption sites and is indicative of the non-linearity of the sorption isotherm. When $N=1$, the Freundlich equation approaches a linear model and $K_{f}$ becomes equal to the $K_{d}$ value, which remains constant across the range of concentrations. If $N>1$, sorption at low metal concentrations may be inhibited by a competing reaction within ligands in the solution, such as soluble organic compounds. $N<1$ indicates the presence of high affinity sites that govern metal sorption at low metal concentrations in the sample.

The metal sorption isotherm was fitted to a linear equation for the concentration range in which a constant slope of $C_{s o r b} v s . C_{e q}$ could be considered. This was the case for the overall concentration range for the amendments investigated here. Therefore, a $\mathrm{K}_{d \text {,linear }}$ value was derived for all amendments and metal combinations, and for all times examined.

\section{Results and discussion}

\subsection{Changes in soil properties during the ageing process}

\subsubsection{Initial conditions}

Table 1 summarises the relevant physicochemical parameters of contaminated soils, as well as total and water-soluble metal concentrations. Soils had very low loss on ignition (LOI) values associated with low organic matter content, low DOC and low CEC values. The S15 soil exhibited a mildly acidic $\mathrm{pH}$, but it also contained significant carbonate content, which 
guaranteed a significant buffering capacity and resulted in the highest ANC value of all of the examined soils. The RIB soil also had a mildly acidic $\mathrm{pH}$ but exhibited negligible carbonate content and low ANC values. The ALJ soil had an acidic pH (lower than 4), which accounted for the negative ANC values.

Regarding total metal content, S15 contained the highest metal concentrations for all metals, followed by ALJ. To evaluate the degree of contamination within the three soils, total metal concentrations were compared with reference levels (maximum allowable concentrations for non-polluted soils) established by the Junta de Andalucía. These values are relevant because the target contaminated soils originated from this region and are subject to its regulation (see Table S1 in the Supplementary Material). Based on this criteria total metal concentrations in the three soils (except for Ni in RIB) exceeded the reference levels. However, total metal concentrations in the RIB soil all fell below the intervention limits for agricultural soils. For this reason, while metal concentrations in the RIB sample exceeded reference levels, they did not require remediation. In contrast, the $\mathrm{S} 15$ and ALJ soils required remediation because their total metal concentrations exceeded the intervention limits, and in certain cases were so bad they exceeded the limits for industrial use $(\mathrm{Cu}, \mathrm{Pb}$ and $\mathrm{Zn}$ for both soils and $\mathrm{Cd}$ for $\mathrm{S} 15$ soil). Of the water-soluble metal concentrations, S15 exhibited the highest Cd concentrations, which represented the highest $\mathrm{Cd}$ extraction yield of the soils examined (greater than $50 \%$ of the total Cd content). The ALJ and RIB soils contained much lower Cd concentrations, which led to lower extraction yields (5\% and $8 \%$, respectively). Extractable $\mathrm{Pb}$ concentrations in all soils were high for the ALJ and S15 soils, although the related extraction yields were lower than $1 \%$. This low extractability was also observed for $\mathrm{Cu}$ in the S15 and RIB soils, while the $\mathrm{Cu}$ extraction yield was significantly higher in the ALJ soil (20\%). Water extraction yields for Zn were relatively low in S15 and RIB (2\% and 3\%, respectively), while they were approximately $11 \%$ for ALJ. However, despite its low extraction yield, the extractable $\mathrm{Zn}$ concentration in the S15 soil was extremely high (6000 meq $\left.\mathrm{kg}^{-1}\right)$. The extractable yield for 
Ni was low in the RIB and S15 soils, and it was approximately $17 \%$ in the ALJ soil. Watersoluble metal concentrations for the soils were compared with the European Council limits for the management of wastes (see Table S1 in the Supplementary Material) (European Council 2003). Under these regulations, the RIB soil is classified as a non-hazardous waste, while the high water-soluble concentrations of all metals in the ALJ soil and of $\mathrm{Cd}$ and $\mathrm{Zn}$ in the S15 soil resulted in these soils being classified as hazardous wastes. Thus, decreasing watersoluble metal concentrations would be an excellent management practice for these soils.

\subsubsection{The effect of ageing on selected soil properties}

Selected soil parameters ( $\mathrm{pH}, \mathrm{ANC}$ and DOC) were monitored during the ageing period and are summarised in Table 1 through a comparison of the T0 and T2 samples. Soil $\mathrm{pH}$ remained constant during the ageing experiments for the ALJ and S15 soils. In contrast, the RIB soil acidified significantly (1.3 $\mathrm{pH}$ units) by the end of the ageing period studied. This behaviour may relate to a partial oxidation of the pyrite present in the RIB soil, which can result in soil acidification (Lacal 2003). This process was not observed in the ALJ soil, which also contained considerable pyrite content, because it had a much lower initial $\mathrm{pH}$ (2.2).

The ANC values of all soils remained roughly constant throughout the ageing period. The significant relative decrease in ANC noticed in the RIB soil was likely due to the acidification of the sample. The DOC content in all soils remained low throughout the ageing process and even decreased slightly at the end of the study period.

\subsection{Changes in amendment properties during the ageing process}

\subsubsection{Initial conditions}

Table 2 summarises some physicochemical parameters of the amendments. All amendments exhibited an alkaline $\mathrm{pH}$, and had higher FC (all over 100\%) and CEC values than the soils. MOW2 had a high ANC value, much higher than that found in the soils and nearly one order 
of magnitude higher than that of the biochars. LOI content ranged from $60 \%$ in MOW2 to approximately $95 \%$ in the two biochars. Conversely, MOW2 had the highest DOC content, followed by BS and BF. The latter had a much lower DOC content, which was of the same order of magnitude as the soil samples. The LOI and DOC content in the amendment samples did not correlate, indicating that the ratio between solid and soluble organic matter strongly varied depending on the amendment.

The total metal content in the three amendments was low, much lower than the maximum concentration established for the addition of organic amendments to agricultural soils in Spain (BOE 2005). MOW2 consistently exhibited the highest total metal concentrations, whereas BS had the lowest. In most cases, the low metal concentrations in the amendments resulted in the dilution of total metal concentrations in the soil+amendment mixtures, with the exception of MOW2 added to RIB, where both samples had similar total metal concentrations for certain metals.

Although extraction yields of water-soluble metal concentrations for the amendments could occasionally be greater than those for the soils, the resulting concentrations were systematically lower than those obtained from the soil samples. Given the dose of amendments applied to soils and the low soluble metal content in these amendments, the contribution of the amendments to the pool of water-soluble metals in the soil+amendment mixtures was considered negligible. Comparing the metal soluble concentrations of the amendments with the European Council's limits for the management of wastes (European Council 2003) indicated that the three amendments would be classified as non-hazardous waste.

\subsubsection{The effect of ageing on selected amendment properties}

Certain parameters ( $\mathrm{pH}, \mathrm{ANC}, \mathrm{CEC}$ and DOC) were monitored during the ageing period and are summarised in Table 2 by comparing the $\mathrm{T} 0$ and $\mathrm{T} 2$ samples. The $\mathrm{pH}$ of the amendments 
remained reasonably constant within the alkaline range, although a moderate decrease of 0.7 $\mathrm{pH}$ units was recorded for the BS biochar. The slight decrease in this $\mathrm{pH}$ may be related to the formation of acid organic functional groups associated with the natural oxidation of organic matter, which has a lower impact on samples with an already low pH (Hale et al. 2011).

The slight increase in the CEC and ANC values for the T2 samples, suggested the oxidation of functional groups on the surface of the organic amendments, which was consistent with reported data (Mukherjee et al. 2014). These two latter parameters were correlated $(\mathrm{R}=0.82)$, thus confirming that the functional groups responsible for the CEC were also responsible for the buffering capacity of the amendments. Finally, slight increases or decreases in DOC content were observed depending on the examined amendment, indicating that DOC was not strongly affected by the ageing process.

\subsubsection{Changes in the sorption capacity of amendments due to the ageing process}

Changes in the sorption capacity of the amendments during the ageing experiments were also tested for $\mathrm{Cd}$ and $\mathrm{Cu}$, because sorption patterns may provide significant information that partially justifies changes in the metal leaching patterns of the soil+amendment mixtures. The isotherms obtained at T0, T1 and T2 are presented in Figure S1 in the Supplementary Material. Table 3 summarises the main sorption parameters of $\mathrm{Cd}$ and $\mathrm{Cu}$ derived from the data and fitting of the respective sorption isotherms.

Sorption data for the T0 samples indicated that the $K_{d}$ parameter varied within a short range according to changes in the initial metal concentrations for all of the amendments. Differences between $K_{d, \min }$ and $K_{d, \max }$ values were generally lower than 2-fold. For Cd, amendment sorption capacity decreased in the following order: MOW2 $>$ BS $>$ BF. This was similar to the sequence of CEC and ANC values in the amendments, suggesting that exchange sites played a key role in $\mathrm{Cd}$ sorption. In the case of $\mathrm{Cu}$, the $K_{d}$ values were inverse to the DOC content of the amendments and followed the sequence BF $>$ BS > MOW2. This behaviour 
was consistent with the high affinity of $\mathrm{Cu}$ to form stable complexes with organic ligands in solution.

The obtained isotherms were satisfactorily fitted with the Freundlich equation with $\mathrm{R}^{2}>0.99$. In the case of $\mathrm{Cd}, N$ values were always lower than 1 , indicating sorption of $\mathrm{Cd}$ at high affinity sites in low concentrations, but at lower affinity sites in higher concentrations. This suggests that ionic exchange mechanisms may govern sorption. That is, $K_{d}$ was predicted to continuously decrease with increasing initial Cd concentrations. Moreover, the $K_{f}$ values were lower than $K_{d, \min }$, since they were derived from a extrapolated scenario in which $C_{e q}$ is 1 meq $\mathrm{L}^{-1}$, in this case for $N<1$. For $\mathrm{Cu}, \mathrm{BF}$ exhibited $N<1$, indicating sites of decreasing affinity as $\mathrm{Cu}$ concentrations increased, as was observed for $\mathrm{Cd}$. The amendments with higher DOC contents (MOW2 and BS) exhibited $N>1$, suggesting that, at low concentrations, $\mathrm{Cu}$ was mostly associated with organic matter in solution, whereas when initial $\mathrm{Cu}$ concentrations increased, the competitive role of dissolved organic matter decreased and the sorption of $\mathrm{Cu}$ increased. As a result, $K_{f}$ values for these cases were generally higher than $K_{d \text {,max }}$, because this value was also derived by extrapolating the $C_{s o r b}$ vs. $C_{e q}$ isotherm to a $C_{e q}$ value of 1 meq $\mathrm{L}^{-1}$, but for $\mathrm{N}>1$.

As the $K_{f}$ estimation was strongly dependent on the $N$ value, and a direct comparison of the metal+amendment scenarios would be compromised, comparisons were better made by fitting sorption data to a linear model. Thus, $K_{\text {d,linear }}$ could be calculated for all cases at the lowest metal concentration values, resulting in a satisfactory fit, where $\mathrm{R}^{2}>0.9$. The fitted $K_{d, \text { linear }}$ parameters resulted in the same relative sequence of sorption among amendments as $K_{d, \min }$ and $K_{d, \text { max }}$ for both $\mathrm{Cd}$ and $\mathrm{Cu}$. Therefore, $K_{\text {d, linear }}$ was considered a robust parameter in the evaluation of the effect of ageing on an amendment's sorption capacity. In general, minor variations were observed in the $K_{d, \min }$ and $K_{d, \max }$, and consistent variations were observed for $K_{d \text {,linear }}$ as a result of ageing, which were consistent with the minor changes in the physicochemical parameters of the amendments, including $\mathrm{pH}, \mathrm{DOC}, \mathrm{ANC}$ and CEC. The 
consistent increase in $K_{d, \text { linear }}$ for Cd in the BS biochar was an exception. This suggests that the sorption capacity of the amendments may be reasonably stable (or even increasing) over the ageing period. The relatively high $K_{d}$ values observed in a few cases (e.g., Cd-MOW2, or $\mathrm{Cu}$ in biochars) should be considered an additional factor affecting metal availability in soil+amendment mixtures.

\subsection{Changes in soil+amendment mixture properties during the ageing process}

\subsubsection{Initial conditions}

The effect of soil amendments on selected soil properties ( $\mathrm{pH}, \mathrm{ANC}$ and DOC) is summarised in Table S2 (T0 samples) (see the Supplementary Material). Every mixture had either a similar or higher $\mathrm{pH}$ than the untreated soils. The amendments with the greatest effect on $\mathrm{pH}$ were not those with the highest $\mathrm{pH}$, but those with the highest $\mathrm{ANC}$, that is, those with the highest buffering capacity. Accordingly, changes in $\mathrm{pH}$ and ANC were more relevant in soils with lower ANC values. The addition of amendments led to a minor increase in the $\mathrm{pH}$ of the S15 soil mixtures because this soil already had a high ANC. In the case of the RIB soil, which had a lower ANC, the amendments led to a slight increase in the $\mathrm{pH}$ of the resulting mixtures (1.1 for MOW2, 0.7 for BF and 1.6 for BS). Changes in the $\mathrm{pH}$ of the ALJ soil were strongly dependent of the amendment used. The addition of MOW2 resulted in a strong increase in soil $\mathrm{pH}$ (2.5 units of $\mathrm{pH})$, whereas biochars had no effect on the mixture's $\mathrm{pH}$ because the buffering capacity of these two amendments was insufficient to have an effect on such an acidic soil. The same reasoning can be used to explain changes in ANC after amendments were added. Soil mixtures with MOW2 resulted in increased ANC values. The largest impact was seen in the ALJ soil, which had the lowest ANC, and the smallest effect occurred in the S15 soil, which already possessed high ANC levels. The RIB-BS mixture exhibited a minor decrease in $\mathrm{pH}$ after the ageing period ( $\mathrm{T} 2$ samples), which was consistent with the $\mathrm{pH}$ decrease observed for the RIB soil and the BS amendment. The rest of the cases exhibited 
non-significant changes in $\mathrm{pH}$ and $\mathrm{ANC}$ as a result of the ageing experiment, which was consistent with the absence of significant variations in the $\mathrm{pH}$ and ANC values observed in the relevant amendments and soils.

With respect to DOC, the addition of MOW2 and BS amendments led to a slight increase in the DOC concentrations in the mixtures at T0 for untreated soils, as was expected based on the higher DOC levels in those amendments; in contrast, this parameter was not significantly modified by the addition of BF. Based on our observations, the ageing process did not lead to a significant or consistent modification of DOC in the soil+amendment mixtures.

\subsubsection{Changes in water extractable metal concentrations due to the addition of amendments} and ageing

Figure 1 summarises the leaching of target metals in the soil+amendment mixtures (T0 samples), with untreated soil taken as a control, as well as the effect of ageing on metal leaching in soils and soil+amendment mixtures (T1 and T2 samples).

\section{The case of the S15 soil}

At the initial time (T0), leaching of all metals in the S15 soil was very low (within the 0.05$3 \%$ range), with the exception of $\mathrm{Cd}(50 \%)$. The high total metal concentration suggested that metal concentrations in the extracts were likely very high, despite the low extraction yields, as was the case for $\mathrm{Zn}$ (approximately $6000 \mathrm{mg} \mathrm{kg}^{-1}$ ) and for $\mathrm{Cd}$ (approximately $500 \mathrm{mg} \mathrm{kg}^{-1}$ ). As expected by the already low extraction yields and high buffer capacity of this soil, a slight decrease in metal extractability was only observed for $\mathrm{Cd}$ and $\mathrm{Zn}$ when MOW2 and BS amendments were added to the soil; the effect was less pronounced for BF. These changes could be partially explained by the fact that BS and MOW2 had high $K_{d}(\mathrm{Cd})$ values, even greater than those expected in soils (Sauvé et al. 2000), and a similar sorption pattern in the amendments could be anticipated for $\mathrm{Zn}$ based on the similarity of their sorption behaviour 
with that of $\mathrm{Cd}$. For $\mathrm{Cu}$ and $\mathrm{Pb}$, non-significant changes occurred after the application of the amendments; thus, no additional role on decreasing metal extractability could be attributed to sorption mechanisms.

Ageing of the S15 samples did not change the amendments' effect pattern, which was consistent with the lack of changes in the amendment properties due to the ageing process. Major changes observed between the $\mathrm{T} 0$ and $\mathrm{T} 2$ samples in the extractability of specific metals were attributed to changes in the metal-soil interactions caused by the drying-wetting cycles. The drying process accelerated the process of natural attenuation, during which the metals are able to be sorbed by inner sphere mechanisms instead of outer sphere mechanisms because of the loss of water molecules, causing them to become less reversibly sorbed (Gerson et al. 2008).

\section{The case of the RIB soil}

At the initial time (T0 samples), metal extraction yields for the RIB soil followed the same trend as observed for the S15 soil. The relatively low metal concentrations in the extracts were related to both low total metal concentration and low extraction yields. $\mathrm{Pb}$ and $\mathrm{Cu}$ exhibited the lowest extraction yields $(<0.5 \%)$, while $\mathrm{Ni}$ and $\mathrm{Zn}$ were also in the low value range (2\% and $3 \%$, respectively). On the other hand, $\mathrm{Cd}$ had the highest, but still moderated extraction yield (8\%). As anticipated, the significant changes in the $\mathrm{pH}$ and ANC values in the RIB mixtures caused by the addition of the amendments resulted in a significant decrease in leachable concentrations of $\mathrm{Zn}, \mathrm{Cd}$ and $\mathrm{Ni}$ in the mixtures when compared with the untreated soil. However, the minor role of the specific sorption increase should not be disregarded, especially for $\mathrm{Ni}$ and $\mathrm{Cd}$. In this case, MOW2 and BS provoked larger reductions in the extraction yield than $\mathrm{BF}$, which was consistent with their greater $K_{d}$ related to $\mathrm{Cd}$. The amendments had a minor effect on the extractable concentrations of $\mathrm{Cu}$ and $\mathrm{Pb}$, despite the 
changes in $\mathrm{pH}$ and $\mathrm{ANC}$, because of the extremely low extraction yields for these metals in the RIB soil.

With respect to the effect of the ageing on metal extractability, the decrease in the leachable concentrations of metals persisted over time in the soil+amendment mixtures, even when slight increases in the extractable concentrations were observed in the soil without amendments (as was the case of $\mathrm{Zn}$ ). Further decreases over time were observed for $\mathrm{Ni}$ and Cd. As already observed for the S15 soils, this confirmed the stability of the amendments added to contaminated soils over time.

\section{The case of the ALJ soil}

At the initial stage ( $\mathrm{T} 0$ samples), high concentrations of $\mathrm{Cu}, \mathrm{Pb}$ and $\mathrm{Zn}$ were observed in the extracts due to the low $\mathrm{pH}$ value of this soil. Given the total metal concentration, this led to metal extraction yields in the untreated ALJ soil that were generally higher than those for the other two soils: $5 \%, 20 \%, 17 \%$ and $11 \%$ for $\mathrm{Cd}, \mathrm{Cu}, \mathrm{Ni}$ and $\mathrm{Zn}$, respectively. The exception was $\mathrm{Pb}$, which also had an extremely low extraction yield (lower than $0.5 \%$ ). The addition of the MOW2 amendment led to a significant decrease in leachable concentrations of all metals, as this material increased the $\mathrm{pH}$ of the soil by more than two units. Conversely, no change was observed after the addition of BS and BF because the ANC of these amendments was insufficient to increase the $\mathrm{pH}$ of such an acidic soil.

In general, the changes in metal extractability observed in the soil+amendment mixtures at $\mathrm{T} 0$ were maintained throughout the ageing process. Therefore, the positive effect of the MOW2 amendment and the leachability pattern of the other two mixtures were constant even after being subjected to the ageing process. 


\section{Conclusions}

In the present study minor changes in the physicochemical properties of organic amendments occurred during the ageing process. In general, minor increases in CEC and ANC due to the ageing process were observed, whereas $\mathrm{pH}$ and DOC content remained almost constant. The sorption capacity of the amendments was generally not affected by ageing either. Once the soils were amended, the addition of the compost and the biochars led to a beneficial effect, decreasing metal extractability in the resulting mixtures, especially in the soils in which $\mathrm{pH}$ and ANC increased. Moreover, DOC did not significantly change in the mixtures during the ageing period. Of the amendments, the MOW2 compost seemed to be the most promising material. Decreases in extractable metal concentrations observed at the initial stage were maintained throughout the ageing period tested, revealing that the effect of the amendments would persist over time, as required for a robust soil remediation strategy.

\section{Acknowledgements}

This research was supported by the Ministerio de Economía y Competitividad (CTM201455191) and the Generalitat de Catalunya (AGAUR 2014SGR1277). ICP-OES and ICP-MS analyses were performed at the CCiT of the Universitat de Barcelona. The authors wish to thank Ecoparc de Barcelona for supplying the MOW2 compost. A. Venegas thanks CONICYT Chile for a pre-doctoral fellowship.

\section{References}

Adriano DC (2001) Trace elements in terrestrial environments: Biogeochemistry, bioavailability and risks of metals, $2^{\text {nd }}$ ed. Springer, New York, NY, USA 
Beesley L, Moreno-Jiménez E, Gomez-Eyles JL (2010) Effects of biochar and greenwaste compost amendments on mobility, bioavailability and toxicity of inorganic and organic contaminants in a multi-element polluted soil. Environ Pollut 158:2282-2287

BOE (2005) Real Decreto 824, de 8 de Julio, sobre productos fertilizantes. BOE 171, España

European Council (2003) European Council Decision 2003/33/CE establishing criteria and procedure for the acceptance of waste at landfills pursuant to Article 16 and Annex II to Directive 1999/31/EC. Off. J. Eur. Communities, EU Commision, Brussels, Belgium

Gerson AR, Anastasio C, Crowe S, Fowle D, Guo B, Kennedy I, Lombi E, Nico PS, Marcus MA, Martin RR, Naftel SJ, Nelson AJ, Paktunc D, Roberts JA, Weisener CG, Werner ML (2008) Chapter 7. Frontiers in assessing the role of chemical speciation and natural attenuation on the bioavailability of contaminants in the terrestrial environment. Dev Soil Sci 32:99-136

Hale SE, Hanley K, Lehmann J, Zimmerman A, Cornelissen G (2011) Effects of chemical, biological, and physical aging as well as soil addition on the sorption of pyrene to activated carbon and biochar. Environ Sci Technol 45:10445-10453

Hooda PS (2010) Assessing bioavailability of soil trace elements, in: Hooda, P.S. (Ed.), Trace elements in soils. John Wiley and Sons, Chichester, U.K., pp. 229-266

Houben D, Pircar J, Sonnet P (2012) Heavy metal immobilization by cost-effective amendments in a contaminated soil: effects on metal leaching and phytoavailability . J Geochem Explor 123:87-94. 
Junta de Andalucía (1999) Los criterios y estándares para declarar un suelo contaminado en Andalucía y la metodología y técnicas de toma de muestra y análisis para su investigación. España

Kabata-Pendias A (2011) Trace elements in soils and plants, $4^{\text {th }}$ ed. CRC Press, Boca Raton, Florida, USA

Khan FI, Husain T, Hejazi R (2004) An overview and analysis of site remediation technologies. J Environ Manage 71:95-122.

Khokhotva O, Waara S (2010) The influence of dissolved organic carbon on sorption of heavy metals on urea-treated pine bark. J Hazard Mater 173:689-696

Kumpiene J, Lagerkvist A, Maurice C (2008) Stabilization of $\mathrm{As}, \mathrm{Cr}, \mathrm{Cu}, \mathrm{Pb}$ and $\mathrm{Zn}$ in soil using amendments: a review. Waste Manag 28:215-225

Lacal J (2003) Study of fractionation and potential mobility of metal in sludge from pyrite mining and affected river sediments: changes in mobility over time and use of artificial ageing as a tool in environmental impact assessment. Environ Pollut 124:291-305.

Lee T.-M., Lai, H.Y., Chen, Z.S., 2004. Effect of chemical amendments on the concentration of cadmium and lead in long-term contaminated soils. Chemosphere 57, 1459-1471.

Martínez, CE, Jacobson AR, McBride MB (2003) Aging and temperature effects on DOC and elemental release from a metal contaminated soil. Environ Pollut 122:135-143

Mukherjee A, Zimmerman AR, Hamdan R, Cooper WT (2014) Physicochemical changes in pyrogenic organic matter (biochar) after 15 months of field aging. Solid Earth 5:693704 
Nwachukwu OI, Pulford ID (2008) Comparative effectiveness of selected adsorbant materials as potential amendments for the remediation of lead, copper and zinc contaminated soil. Soil Use Manag 24:199-207

OECD (2000) OECD Guideline 106. Guideline for the testing of chemicals: Adsorptiondesorption using a batch equilibrium method

Sastre J, Rauret G, Vidal M (2006) Effect of the cationic composition of sorption solution on the quantification of sorption-desorption parameters of heavy metals in soils. Environ Pollut 140:322-339

Sauvé S, Hendershot W, Allen HE (2000) Solid-solution partitioning of metals in contaminated soils: dependence on $\mathrm{pH}$, total metal burden and organic matter. Environ Sci Technol 34:1125-1131 
Table 1 Main parameters of soils

\begin{tabular}{|c|c|c|c|c|}
\hline Parameter & & S15 & RIB & ALJ \\
\hline $\mathrm{pH}$ & & 6.3 & 6.4 & 2.2 \\
\hline ANC $\left(\right.$ meq $\left.\mathrm{kg}^{-1}\right)$ & & 1960 & 60 & -440 \\
\hline Moisture (\%) & & 7.9 & 1.1 & 1.3 \\
\hline $\mathrm{FC}(\%)$ & & 34 & 29 & 21 \\
\hline LOI $(\%)$ & & 0.9 & 1.0 & 1.0 \\
\hline $\mathrm{DOC}\left(\mathrm{mg} \mathrm{L}^{-1}\right)$ & & 12 & 21 & 18 \\
\hline $\mathrm{CaCO}_{3}(\%)$ & & 16 & $<$ l.q. & $<$ l.q. \\
\hline $\mathrm{CEC}\left(\mathrm{cmol}_{\mathrm{c}} \mathrm{kg}^{-1}\right)$ & & 13 & 6.9 & 3.0 \\
\hline Sand $(\%$, wrt mineral matter) & & 63.9 & 76.5 & 34.2 \\
\hline Clay (\%, wrt mineral matter) & & 9.5 & 7.2 & 18.2 \\
\hline \multirow[t]{2}{*}{$\mathrm{Cd}\left(\mathrm{mg} \mathrm{kg}^{-1}\right)$} & $\mathrm{TC}$ & 10200 & 4 & 15 \\
\hline & WS & 5140 & 0.3 & 0.8 \\
\hline \multirow[t]{2}{*}{$\mathrm{Cu}\left(\mathrm{mg} \mathrm{kg}^{-1}\right)$} & $\mathrm{TC}$ & 16430 & 120 & 1610 \\
\hline & WS & 8.1 & 0.6 & 330 \\
\hline \multirow[t]{2}{*}{$\mathrm{Ni}\left(\mathrm{mg} \mathrm{kg}^{-1}\right)$} & $\mathrm{TC}$ & 150 & 26 & 60 \\
\hline & WS & 4.9 & 0.6 & 9.9 \\
\hline \multirow[t]{2}{*}{$\mathrm{Pb}\left(\mathrm{mg} \mathrm{kg}^{-1}\right)$} & TC & 91520 & 260 & 12370 \\
\hline & WS & 43 & 0.5 & 60 \\
\hline \multirow[t]{2}{*}{$\mathrm{Zn}\left(\mathrm{mg} \mathrm{kg}^{-1}\right)$} & $\mathrm{TC}$ & 275500 & 350 & 3295 \\
\hline & WS & 6030 & 9.8 & 360 \\
\hline \multicolumn{5}{|c|}{ Effect of aging in selected soil properties } \\
\hline \multirow[t]{2}{*}{$\mathrm{pH}$} & T0 & 6.3 & 6.4 & 2.2 \\
\hline & $\mathrm{T} 2$ & 6.4 & 5.1 & 2.2 \\
\hline \multirow[t]{2}{*}{$\mathrm{ANC}\left(\right.$ meq $\left.\mathrm{kg}^{-1}\right)$} & T0 & 1960 & 60 & -440 \\
\hline & $\mathrm{T} 2$ & 1865 & 25 & -350 \\
\hline \multirow[t]{2}{*}{$\mathrm{DOC}\left(\mathrm{mg} \mathrm{C} \mathrm{L}^{-1}\right)$} & T0 & 10 & 20 & 20 \\
\hline & $\mathrm{T} 2$ & 5 & 10 & 15 \\
\hline
\end{tabular}

ANC: acid neutralization capacity; FC: field capacity; LOI: loss on ignition; DOC: dissolved organic carbon; CEC:cation exchange capacity

TC: total content; WS: water soluble; 1.q.: limit of quantification 
Table 2 Main parameters of amendments

\begin{tabular}{|c|c|c|c|c|}
\hline Parameter & & MOW2 & $\mathrm{BF}$ & $\mathrm{BS}$ \\
\hline $\mathrm{pH}$ & & 8.1 & 8.6 & 9.4 \\
\hline $\operatorname{ANC}\left(\right.$ meq $\left.\mathrm{kg}^{-1}\right)$ & & 4180 & 420 & 725 \\
\hline Moisture (\%) & & 6.0 & 4.5 & 6.0 \\
\hline $\mathrm{FC}(\%)$ & & 175 & 116 & 100 \\
\hline LOI $(\%)$ & & 60 & 95 & 95 \\
\hline $\mathrm{DOC}\left(\mathrm{mg} \mathrm{L}^{-1}\right)$ & & 475 & 10 & 220 \\
\hline $\mathrm{CEC}\left(\mathrm{cmol}_{\mathrm{c}} \mathrm{kg}^{-1}\right)$ & & 65 & 25 & 55 \\
\hline \multirow[t]{2}{*}{$\mathrm{Cd}\left(\mathrm{mg} \mathrm{kg}^{-1}\right)$} & $\mathrm{TC}$ & 6.4 & 1.2 & 0.6 \\
\hline & WS & 0.4 & 0.8 & 0.1 \\
\hline \multirow[t]{2}{*}{$\mathrm{Cu}\left(\mathrm{mg} \mathrm{kg}^{-1}\right)$} & $\mathrm{TC}$ & 150 & 33 & 20 \\
\hline & WS & 7.3 & 0.4 & 0.2 \\
\hline \multirow[t]{2}{*}{$\mathrm{Ni}\left(\mathrm{mg} \mathrm{kg}^{-1}\right)$} & $\mathrm{TC}$ & 75 & 15 & 1.6 \\
\hline & WS & 0.9 & $<$ l.q. & $<$ l.q. \\
\hline \multirow[t]{2}{*}{$\mathrm{Pb}\left(\mathrm{mg} \mathrm{kg}^{-1}\right)$} & TC & 175 & 4.2 & 1.7 \\
\hline & WS & 1.9 & 1.6 & 1.0 \\
\hline \multirow[t]{2}{*}{$\mathrm{Zn}\left(\mathrm{mg} \mathrm{kg}^{-1}\right)$} & $\mathrm{TC}$ & 430 & 75 & 105 \\
\hline & WS & 2.1 & 9.2 & 0.8 \\
\hline \multicolumn{5}{|c|}{ Effect of aging in selected amendment properties } \\
\hline \multirow[t]{2}{*}{$\mathrm{pH}$} & T0 & 8.1 & 8.6 & 9.4 \\
\hline & $\mathrm{T} 2$ & 8.0 & 8.3 & 8.7 \\
\hline \multirow[t]{2}{*}{ ANC (meq kg $\left.{ }^{-1}\right)$} & T0 & 4180 & 420 & 725 \\
\hline & $\mathrm{T} 2$ & 4915 & 515 & 790 \\
\hline \multirow[t]{2}{*}{$\mathrm{CEC}\left(\mathrm{cmol}_{\mathrm{c}} \mathrm{kg}^{-1}\right)$} & T0 & 65 & 25 & 55 \\
\hline & $\mathrm{T} 2$ & 85 & 30 & 60 \\
\hline \multirow[t]{2}{*}{$\mathrm{DOC}\left(\mathrm{mg} \mathrm{L}^{-1}\right)$} & T0 & 475 & 10 & 220 \\
\hline & $\mathrm{T} 2$ & 390 & 6 & 245 \\
\hline
\end{tabular}

ANC: acid neutralization capacity; FC: field capacity; LOI: loss on ignition; DOC: dissolved organic carbon; CEC:cation exchange capacity

TC: Total content; WS: Water soluble; l.q.: limit of quantification 
Table 3 Sorption parameters of amendments

\begin{tabular}{|c|c|c|c|c|c|c|}
\hline \multicolumn{2}{|l|}{ Metal } & $\begin{array}{l}K_{d, \min } \\
\left(\mathrm{L} \mathrm{kg}^{-1}\right)\end{array}$ & $\begin{array}{l}K_{d, \max } \\
\left(\mathrm{L} \mathrm{kg}^{-1}\right)\end{array}$ & $K_{f}$ & $N$ & $\begin{array}{l}K_{d, \text { linear }} \\
\left(\mathrm{L} \mathrm{kg}^{-1}\right)\end{array}$ \\
\hline \multicolumn{7}{|l|}{$\mathrm{Cd}$} \\
\hline \multirow[t]{3}{*}{ MOW2 } & T0 & 2320 & 3265 & $1040(170)$ & 0.81 & $2640(90)$ \\
\hline & $\mathrm{T} 1$ & 2440 & 3510 & $1020(190)$ & 0.81 & $2790(70)$ \\
\hline & $\mathrm{T} 2$ & 2190 & 3525 & $1010(110)$ & 0.83 & $2400(80)$ \\
\hline \multirow[t]{3}{*}{$\mathrm{BF}$} & T0 & 170 & 320 & $80(20)$ & 0.64 & $240(10)$ \\
\hline & $\mathrm{T} 1$ & 150 & 270 & $80(10)$ & 0.67 & $200(10)$ \\
\hline & $\mathrm{T} 2$ & 100 & 210 & $60(5)$ & 0.67 & $125(10)$ \\
\hline \multirow[t]{3}{*}{$\mathrm{BS}$} & T0 & 770 & 1410 & $325(10)$ & 0.76 & $860(50)$ \\
\hline & $\mathrm{T} 1$ & 1725 & 3205 & $680(60)$ & 0.79 & $1830(100)$ \\
\hline & $\mathrm{T} 2$ & 1640 & 3320 & $500(150)$ & 0.73 & $1700(170)$ \\
\hline \multicolumn{7}{|l|}{$\mathrm{Cu}$} \\
\hline \multirow[t]{3}{*}{ MOW2 } & T0 & 915 & 1445 & 4840 (670) & 1.30 & $1715(60)$ \\
\hline & $\mathrm{T} 1$ & 825 & 1530 & $5760(1440)$ & 1.32 & $1740(40)$ \\
\hline & $\mathrm{T} 2$ & 620 & 1585 & $3250(1830)$ & 1.27 & 1365 (110) \\
\hline \multirow[t]{3}{*}{$\mathrm{BF}$} & T0 & 2605 & 4860 & $610(70)$ & 0.72 & $2350(310)$ \\
\hline & $\mathrm{T} 1$ & 3930 & 8200 & 900 (100) & 0.70 & $4750(320)$ \\
\hline & $\mathrm{T} 2$ & 2535 & 7370 & $540(40)$ & 0.66 & $3180(240)$ \\
\hline \multirow[t]{3}{*}{$\mathrm{BS}$} & T0 & 1770 & 2255 & $2590(1170)$ & 1.04 & $2140(50)$ \\
\hline & $\mathrm{T} 1$ & 1405 & 2630 & $3280(1560)$ & 1.09 & $2140(50)$ \\
\hline & $\mathrm{T} 2$ & 1495 & 2415 & 3375 (1950) & 1.07 & $2370(80)$ \\
\hline
\end{tabular}


Fig. 1 Effect of aging on the leaching of heavy metals in soils and soil+amendment mixtures. Error bars indicate one standard deviation.
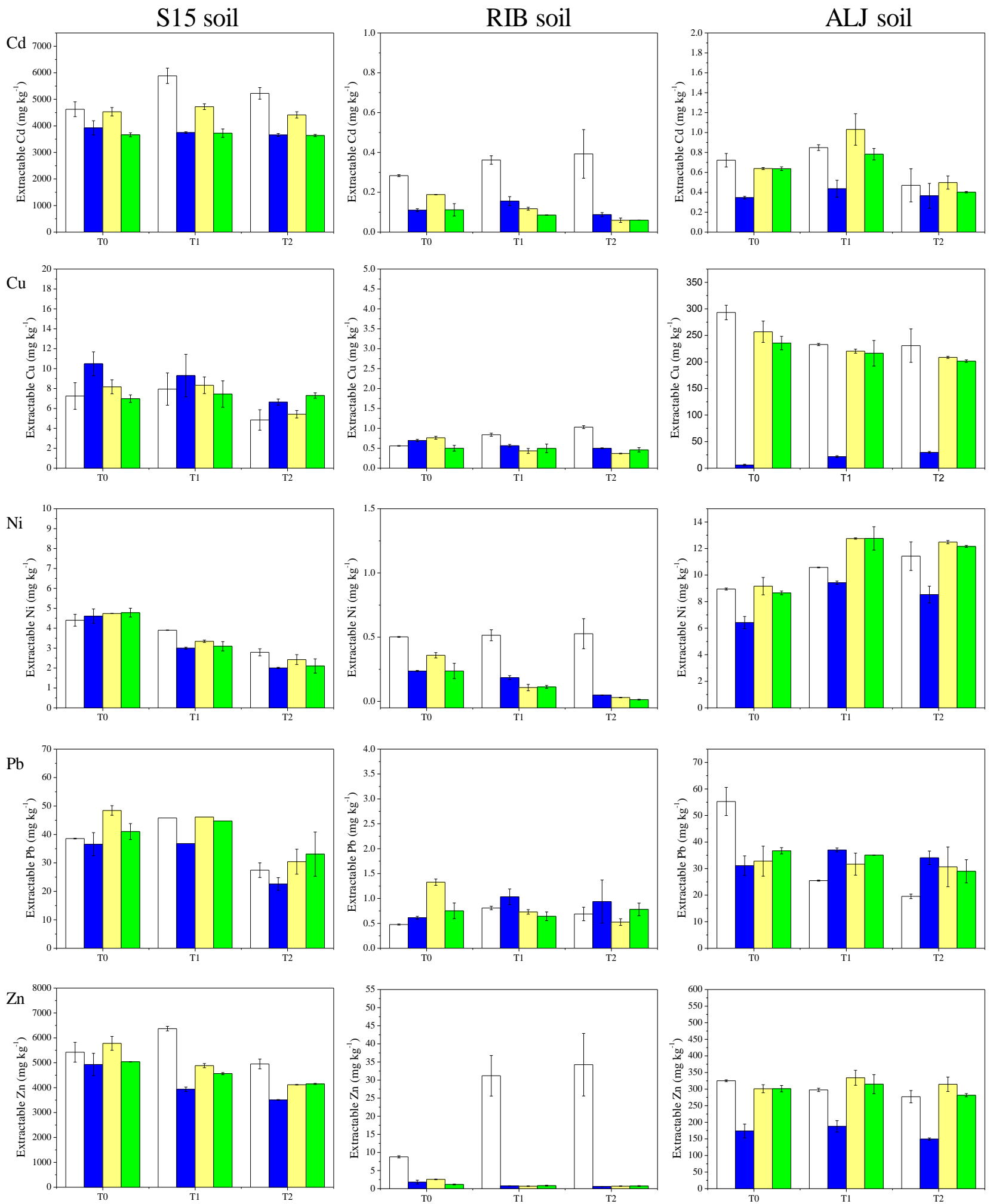

$\square$ Untreated soil

Soil+MOW2 Soil+BF

Soil+BS 


\section{Supplementary material}

Effect of ageing on the availability of heavy metals in soils amended with compost and biochar: evaluation of changes in soil and amendment properties

Andrea Venegas, Anna Rigol, Miquel Vidal

\section{Material and methods}

\section{Sample characterisation}

The $\mathrm{pH}$ of each soil and amendment was measured in deionised water using a solutionto-solid ratio of $10 \mathrm{~mL} \mathrm{~g}^{-1}$. Field capacity (FC) was determined by wetting the samples until a saturated paste was obtained, and then the paste was centrifuged at 0.33 bar $(75 \mathrm{x}$ $g$ during $30 \mathrm{~min}$ ). The samples were then dried at $105^{\circ} \mathrm{C}$ to constant weight. The resulting weight loss was the FC. Particle size distribution was determined using the pipette method and was based on the varying settling velocity in a fluid medium of the different particle sizes (Burt, 2004).

The buffering capacity of the samples was examined using a $\mathrm{pH}$ titration test (CEN/TS, 2006). This test also allowed for the determination of the acid neutralisation capacity (ANC) of the samples, which is defined as the quantity of an acid or base (meq $\mathrm{kg}^{-1}$ ) required to shift the initial $\mathrm{pH}$ of a sample to a $\mathrm{pH}$ of 4 . First, the initial $\mathrm{pH}$ of each sample (2 g) was measured in a 1:100 sample/deionised water ratio. Then, consecutive additions of $200 \mu \mathrm{L}$ of $1 \mathrm{~mol} \mathrm{~L}^{-1} \mathrm{HNO}_{3}$ or $1 \mathrm{~mol} \mathrm{~L}^{-1} \mathrm{NaOH}$ were made, and the $\mathrm{pH}$ of the suspension was measured after the sample was stirred for 40 min following each addition. The acid and base additions were repeated until the $\mathrm{pH}$ range of $2-12 \mathrm{had}$ been covered. 
The cationic exchange capacity (CEC) of the amendments and soils was determined by extraction using ammonium acetate (Bower et al., 1952). $5 \mathrm{~g}$ of the sample was put in contact with $30 \mathrm{~mL}$ of $95 \%$ ethanol, and the resulting suspension was shaken end over end for $5 \mathrm{~min}$ and then centrifuged. This procedure was repeated three times to remove the soluble salts, and the supernatants were discarded. $30 \mathrm{~mL}$ of $1 \mathrm{~mol} \mathrm{~L}-1$ ammonium acetate were added to the remaining solid, and the suspension was again shaken end over end for $5 \mathrm{~min}$ and centrifuged. This step was repeated three times, and the supernatants were collected in the same flask. The exchangeable cations $(\mathrm{Ca}, \mathrm{Mg}, \mathrm{K}$, $\mathrm{Na}$ ) in the supernatant were determined using ICP-OES, and the CEC was calculated as the sum of the exchangeable cations.

The loss-on-ignition (LOI) of the samples was determined as the loss of weight of $3 \mathrm{~g}$ of soil (or $10 \mathrm{~g}$ of amendment) at $450^{\circ} \mathrm{C}$ for $16 \mathrm{~h}$. The soil (or amendment) had been previously oven-dried overnight at $110^{\circ} \mathrm{C}$. The dissolved organic carbon (DOC) content was quantified in the water extracts obtained by equilibrating $6 \mathrm{~g}$ of the sample with 60 $\mathrm{mL}$ of deionised water for $48 \mathrm{~h}$. Then, the samples were centrifuged and filtered through a $0.45-\mu \mathrm{m}$ filter, and the DOC content was determined from a water extract that had been previously acidified to $\mathrm{pH} 2$ with $\mathrm{HCl}$. A total organic carbon analyser (Shimatzu TOC-50000) was used to determine DOC.

The total content of trace elements in the soil samples was determined through soil digestion in a closed microwave digestion system (Milestone Ethos Touch Control) following a procedure adapted from EPA 3052 (USEPA, 2008). Briefly, $0.3 \mathrm{~g}$ of the sample were weighed in a PTFE vessel, and $6 \mathrm{~mL}$ of $69 \% \mathrm{HNO}_{3}, 3 \mathrm{~mL}$ of $40 \% \mathrm{HF}$ and $2 \mathrm{~mL}$ of $30 \% \mathrm{H}_{2} \mathrm{O}_{2}$ were added in the first stage. The temperature was gradually increased from $25^{\circ} \mathrm{C}$ to $190^{\circ} \mathrm{C}$ over $15 \mathrm{~min}$, and then the sample was held at a constant temperature for $30 \mathrm{~min}$. After a cooling time of $10 \mathrm{~min}, 16 \mathrm{~mL}$ of $5 \% \mathrm{H}_{3} \mathrm{BO}_{3}$ were 
added to mask the free fluoride ions present in the solution and re-dissolve the fluoride precipitates; and the resulting suspension was subjected to the same digestion procedure as in the first stage. After cooling the extracts to room temperature, they were diluted with deionised water to a final volume of $50 \mathrm{~mL}$ and stored at $4^{\circ} \mathrm{C}$ until analysis.

The water-soluble metal content was quantified from the water extracts obtained after equilibrating a known amount of sample with deionised water in a 1:10 solid:liquid ratio (DIN, 1984) for $48 \mathrm{~h}$ at room temperature. Then, the samples were centrifuged, and the water extract was decanted, filtered and stored at $4^{\circ} \mathrm{C}$ until analysis. Metals were determined in the solutions by inductively coupled plasma optical emission spectroscopy (ICP-OES) using a Perkin-Elmer Model OPTIMA 3200RL. The following emission lines were used for each element determined (nm) Cd: 214.440 and 228.802; $\mathrm{Cu}: 324.752$ and 327.393; Pb: 220.353; Zn: 206.200 and 213.857; Ca: 315.887 and 317.933; Mg: 279.077 and 285.213; K: 766.490; Na: 330.237 and Ni: 231.604. The detection limits using this technique were $0.01 \mathrm{mg} \mathrm{L}^{-1} \mathrm{Cd} ; 0.01 \mathrm{mg} \mathrm{L}^{-1}$ for $\mathrm{Cu} ; 0.1 \mathrm{mg}$ $\mathrm{L}^{-1}$ for $\mathrm{Ni}$; $0.2 \mathrm{mg} \mathrm{L}^{-1}$ for $\mathrm{Pb}$ and $0.025 \mathrm{mg} \mathrm{L}^{-1}$ for $\mathrm{Zn}$. For samples with lower metal concentrations, a Perkin-Elmer ELAN 6000 inductively coupled plasma mass spectrometer was used (ICP-MS). The detection limits of the ICP-MS measurements were $0.02 \mu \mathrm{g} \mathrm{L}^{-1}$ for $\mathrm{Cd} ; 0.1 \mu \mathrm{g} \mathrm{L}^{-1}$ for $\mathrm{Cu} ; 0.2 \mu \mathrm{g} \mathrm{L}{ }^{-1}$ for $\mathrm{Ni} ; 0.05 \mu \mathrm{g} \mathrm{L} \mathrm{L}^{-1}$ for $\mathrm{Pb}$ and 0.2 $\mu \mathrm{g} \mathrm{L}{ }^{-1}$ for $\mathrm{Zn}$. 
Table S1 Reference levels and intervention limits $\left(\mathrm{mg} \mathrm{kg}^{-1}\right)$ for agricultural and industrial soils regulated by the Junta de Andalucía (1999) and water soluble contents $\left(\mathrm{mg} \mathrm{kg}^{-1}\right)$ regulated by Decision 2003/33/CE of the European Council (2003) for the acceptance of waste at landfills

\begin{tabular}{|c|c|c|c|c|c|c|}
\hline & \multicolumn{3}{|c|}{ Junta de Andalucía } & \multicolumn{3}{|c|}{ EC Decision 2003/33/CE } \\
\hline & Reference level $^{\mathrm{a}}$ & Intervention limit ${ }^{\mathrm{b}}$ & & Inert waste & Non-hazardous waste & Hazardous waste \\
\hline $\mathrm{Cd}$ & 2 & 7 & 30 & 0.04 & 1 & 5 \\
\hline $\mathrm{Ni}$ & 40 & 200 & 750 & 0.4 & 10 & 40 \\
\hline $\mathrm{Pb}$ & 100 & 350 & 2000 & 0.5 & 10 & 50 \\
\hline $\mathrm{Zn}$ & 200 & 600 & 3000 & 4 & 50 & 200 \\
\hline
\end{tabular}

${ }^{a}$ Maximum allowable concentration for non-polluted soils, which indicates that $90 \%$ of soils from the region present lower contents.

${ }^{\mathrm{b}}$ Threshold concentration above which the soil is considered contaminated with dangerous levels and urgent remediation process is required. 
Table S2 Effect of aging in selected properties of the soil+amendment mixtures

\begin{tabular}{|c|c|c|c|c|c|c|c|c|c|c|}
\hline & & S15-MOW2 & S15-BF & S15-BS & ALJ-MOW2 & ALJ-BF & ALJ-BS & RIB-MOW2 & RIB-BF & RIB-BS \\
\hline \multirow[t]{2}{*}{$\mathrm{pH}$} & T0 & 6.6 & 6.3 & 6.4 & 4.7 & 2.1 & 2.0 & 7.5 & 7.1 & 7.6 \\
\hline & $\mathrm{T} 2$ & 6.6 & 6.4 & 6.4 & 4.3 & 2.0 & 2.0 & 7.7 & 6.9 & 7.3 \\
\hline ANC & T0 & 2260 & 2070 & 1740 & 35 & -245 & -260 & 305 & 90 & 95 \\
\hline$($ meq kg-1) & $\mathrm{T} 2$ & 2370 & 1855 & 1790 & 15 & -310 & -220 & 360 & 60 & 95 \\
\hline DOC & $\mathrm{T} 0$ & 30 & 10 & 25 & 25 & 15 & 35 & 40 & 15 & 45 \\
\hline$\left(\mathrm{mg} \mathrm{C} \mathrm{L} \mathrm{L}^{-1}\right)$ & $\mathrm{T} 2$ & 30 & 8 & 12 & 20 & 13 & 20 & 30 & 10 & 20 \\
\hline
\end{tabular}

ANC: acid neutralization capacity; DOC: dissolved organic carbon 
Fig. S1 Sorption isotherms of $\mathrm{Cd}$ and $\mathrm{Cu}$ in the amendments at increasing aging time
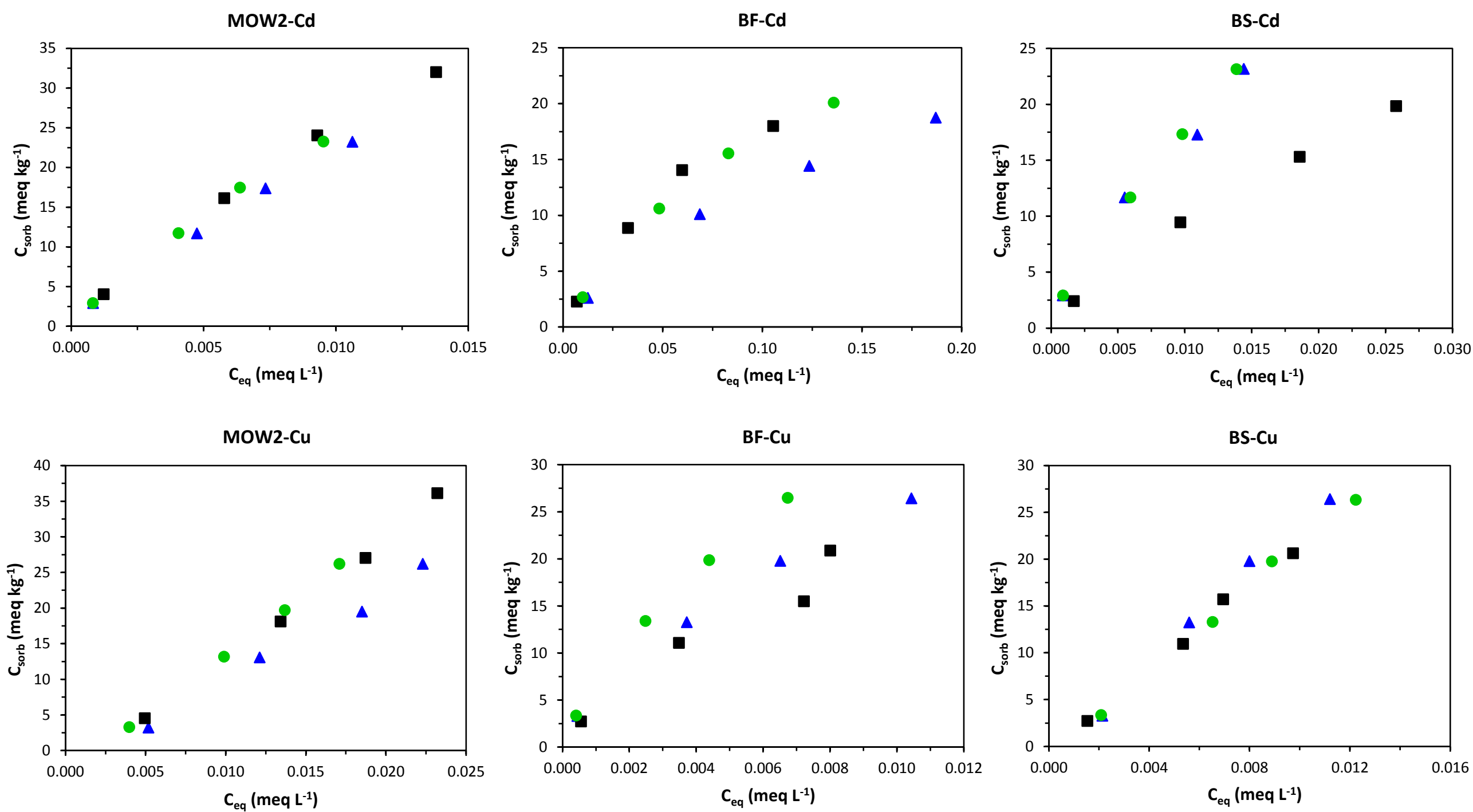

$\boldsymbol{-} \mathrm{T} 0 \bullet \mathrm{T} 1 \boldsymbol{\Delta} \mathrm{T} 2$ 


\section{References}

Burt, R., 2004. Soil survey laboratory methods manual, Investigations reports No 42, Version 4.0. Natural resources conservation services. USDA, U.S. Department of agriculture. Washington D.C. USA.

Bower, C.A., Reitemeier, R.F., Fireman, M., 1952. Exchangeable cation analysis of saline and alkaline soils. Soil Sci. 73, 251-261.

CEN/TS, 2006. CEN/TS 15364. Characterization of waste. Leaching behaviour test. Acid and basic neutralization capacity test. European Comitee of Standarization, Brussels, Belgium.

DIN, 1984. DIN 38414-S4, 1984. German standard methods for the examination of water, waste water and sludge. Group S (sludge and sediments). Determination of leachability by water (S4). Normung, Berlin, Germany.

European Council (2003) European Council Decision 2003/33/CE establishing criteria and procedure for the acceptance of waste at landfills pursuant to Article 16 and Annex II to Directive 1999/31/EC. Off. J. Eur. Communities, EU Commision, Brussels, Belgium.

Junta de Andalucía (1999) Los criterios y estándares para declarar un suelo contaminado en Andalucía y la metodología y técnicas de toma de muestra y análisis para su investigación. España.

USEPA, 2008. Method 3052. Microwave assisted acid digestions of siliceous and organically based matrices, in: Test methods for evaluating solid waste. Physical/chemical methods. SW-546. USEPA. Washington D.C. USA. 